\title{
DESISTERS IN THE MAKING? EXPLORING THE CAPACITY TO DESIST DURING COMMUNITY TRANSITION AMONG A SMALL LONGITUDINAL PANEL OF RELEASEES
}

\author{
Eric Grommon \\ Assistant Professor \\ School of Public and Environmental Affairs \\ Indiana University-Purdue University Indianapolis \\ 801 W. Michigan Street, BS 3027 \\ Indianapolis, IN 46202 \\ $317 / 278-9481$ \\ 317/274-7860 (fax) \\ egrommon@iupui.edu \\ Jason Rydberg \\ Assistant Professor \\ School of Criminology and Justice Studies \\ University of Massachusetts Lowell \\ 113 Wilder Street, HSSB 4th Floor \\ Lowell, MA 01854 \\ 978/934-4173 \\ 978/934-3077 (fax) \\ jason_rydberg@uml.edu
}

\section{Citation}

Grommon, E. \& Rydberg, J. (2016). Desisters in the making? Exploring the capacity to desist during community transition among a small longitudinal panel of releasees. Journal of Crime and Justice. DOI: 10.1080/0735648X.2016.1228470

\section{Funding Acknowledgement}

This work was supported by the U.S. Department of Justice, Office of Justice Programs, Bureau of Justice Statistics [grant numbers 2007-BJS-CX-K036, 2011-BJS-2831]. Any points of view or opinions expressed within this document are those of the authors and do not necessarily represent the position or policies of the Bureau of Justice Statistics. The funding agency did not influence the study design, the analysis of the data, or the preparation of this manuscript. 


\title{
DESISTERS IN THE MAKING? EXPLORING THE CAPACITY TO DESIST DURING COMMUNITY TRANSITION AMONG A SMALL LONGITUDINAL PANEL OF RELEASEES
}

\begin{abstract}
Self-narratives signal readiness for change and the capacity to desist from crime. Utilizing longitudinal interviews with 39 male subjects in a small, industrialized, Midwestern U.S. city, this study explores self-narratives to gain additional understanding about desistance and the malleable components that shape the process. In contrast to existing long-term desistance studies, this research considers the presence of desistance promoting narratives during reentry. Data on three waves of interviews conducted shortly after release and three or more months after the first interview are presented. Results indicate that returning prisoners engage with desistance promoting themes during the immediate reentry process, and that the prevalence and importance of these themes change with additional time in the community. The implications of these findings for reentry policy, practice, and research are discussed.
\end{abstract}

Keywords: Desistance from crime; Prisoner reentry; Parole; Prospective research design; Identity transformation 


\section{DESISTERS IN THE MAKING? EXPLORING THE CAPACITY TO DESIST DURING COMMUNITY TRANSITION AMONG A SMALL LONGITUDINAL PANEL OF RELEASEES}

Over 620,000 individuals were released from prison to local communities in the U.S. in 2013 (Carson 2014). Despite best intentions and desires for conformity, many will not make it through community transition unscathed. National estimates have suggested that $68 \%$ will be rearrested and 50\% will be returned back to prison within three years (Durose, Cooper, and Snyder 2014). Recidivism often happens quickly. Two-thirds of recidivism events will occur within the first post-release year (Durose et al. 2014). Yet, over prolonged periods of time, a majority of those involved in crime will terminate offending behavior. Despite these general trends, numerous questions remain about mechanisms that shape individual desistance trajectories. As this body of literature continues to evolve, there is a need to further understand how subjective factors associated with long-term desistance trends are experienced by individuals during the immediate transition into the community after release from prison. Navigation through this early, contemplative phase of change has the potential to set the stage for long-term identity transformation (Healy and O’Donnell 2008; King 2013).

Much of what is known about the subjective dimensions that promote desistance have been generated from the seminal work of Maruna (2001), who examined self-narratives among a matched cross-sectional sample of 65 individuals extensively involved in criminal activity who had been making an effort to desist or who had actively continued their criminal activity. Individuals moving toward desistance construct their identities in a manner that focuses on redeeming one's stigmatized identity and emphasizes individual agency and generative activities that give meaning to one's life. Alternatively, individuals persisting in their offending behavior 
lived by a condemnation script where the power of the situation determines one's identity, opportunities, and direction in life.

Despite the significance of Maruna's (2001) contribution to our knowledge of subjective desistance factors and how desistance is experienced directly from the perspective of exoffenders, there is a need for further development through research replications and extensions. First, it is not clear whether desistance promoting factors detailed by Maruna (2001) are present during reentry. Maruna's (2001) sample of desisters had been in the community for at least one year prior to being interviewed. Evidence about whether desistance factors are present immediately after correctional system contact is mixed (Farmer, Beech, and King, 2012; Healy and O'Donnell, 2008; King, 2013; Liem and Richardson, 2014) and further confounded by interactions between agency and structure. Second, questions remain about whether desistance promoting factors change over time. There is little doubt that desistance is a process, but attempts to empirically examine the dynamics of the process have utilized retrospective crosssectional research designs. Determining whether desistance promoting factors are present in addition to whether such factors remain stable or change with time can provide important insights on how the desistance process unfolds and enable the identification of intervention points to support identify transformations.

The analyses that follow fills these gaps and contributes to the prisoner reentry and desistance literatures by examining whether and how individuals engage with desistance promoting factors during their immediate transition into the community and how their engagement is shaped by the immediate reentry experience. The contribution of this research is to examine the prevalence and perceived importance of desistance antecedents prospectively during the immediate reentry experience. Specifically, through the use of prospective 
longitudinal panel interviews with individuals recently released from prison, this research seeks to address two primary research questions: first, what are the critical subjective desistance factors individuals identify during the transition from prison to the community and second, how do individual perceptions of the importance of these factors change with continued time in the community. This knowledge has direct implications for prisoner reentry policy and practice as well as for future research on reentry using a desistance framework. The following review introduces and situates desistance capacity as a bridge between the reentry and long-term desistance literatures before presenting the analysis.

\section{DESISTANCE, REENTRY, AND CONTINGENCY}

Recent research has begun to question conceptualizations of and the dynamics between primary (a hiatus in offending) and secondary desistance (conscious internalized maintenance of desistance) through examinations of early desistance narratives held by individuals. Among a sample of probationers in England, King (2013) found no qualitative differences or time ordering between primary and secondary desistance. Active attempts to create a new identity and distance one's current self from past notions of a criminal self were being conducted within the first two months of being on probation. Liem and Richardson (2014) find similar processes being employed by a sample of individuals who had served life sentences. This line of research suggests that rather than primary desistance being an antecedent to secondary desistance, the two forms of desistance occur simultaneously. Additionally, secondary desistance can occur without primary desistance. Analysis of recidivism patterns among a sample of 687 individuals followed 18 years after a New Jersey felony conviction provided evidence of such instantaneous desistance among a quarter of the sample (Kurlychek, Bushway, and Brame 2012). 
These insights contrast with Healy and O'Donnell (2008) who observed delays in transformative identity work. For a sample of 73 probationers in Ireland, early stages of desistance were influenced by the ability of individuals to navigate and overcome challenges associated with a criminal conviction. Here the inability to make material gains constrains efforts to transform. Housing, employment, transportation, identification, clothing, and communitybased service enrollment are some of the most common needs of recently released individuals (Morani, et al. 2011; Shapland and Bottoms 2011). The persistence of unfulfilled needs can deepen disconnects between desires and capabilities to change. Recently released individuals are optimistic about their ability to desist but are unable to create leverage and actualize plans for change (Harris 2011; Shapland and Bottoms 2011).

Taken together, these findings suggest that factors associated with long-term desistance patterns can emerge during initial reentry experiences, but also that individuals do not deploy these resources in a vacuum. Rather, the reentry process structures attempts to engineer identity transformation. In order for individuals to realize identity change they must navigate the material conditions of reentry. Archer (2000) provides a useful theoretical framework to understand these dynamics. Individuals are situated within an environment and must continuously interact within structural constraints of physical (i.e., body-environment relations), practical (i.e., subject-object relations), and social associations (i.e., subject-subject relations). As such, Archer's (2000) human agent actively seeks to achieve health and well-being, fulfills the need to make a living, and generates self-worth through relationships with others. Research on reentry suggests that these associations are important, where success entails navigating practical (i.e., obtaining employment, housing, and treatment) and social associations (i.e., building pro-social peer groups) (Petersilia 2003). 
Previous work has commented on this interplay between agency and structure in desistance. For instance, Maruna (2001) found desisters to speak with a strong sense of agency, internalized self-control and purpose, which is at odds with past selves partially conditioned by circumstance. One's sense of identity is presented as active and powerful despite the various social and economic challenges of a criminal conviction. Indeed, there is evidence to suggest that identity or subjective conceptualizations of one's self precede structure and influences how structural challenges are perceived (Davis et al. 2013; LeBel et al. 2008; Rocque et al., 2016).

At the same time, individuals transitioning to the community are enmeshed in structural conditions constituted by employment (Uggen 2000), relationships (Weaver 2012), marriage (Farrington and West 1995; Laub and Sampson 2003), residential relocation (Kirk 2012), treatment or community services (Veysey, Martinez, and Christian 2013), incarceration (Maruna and Toch 2005; Soyer 2014), and release and reentry (Mears, Cochran, and Siennick 2013). These factors have been offered as adaptive turning points conditioned by one's social environment. Yet, recent research has suggested that individuals must successfully navigate these structures to cultivate reformed identities (King 2013). Leverentz (2014), for instance, found that strong agency narratives perpetually reinforced by self-help programming empowered current and former residents of a halfway house in Chicago serving women coming out of prison, but left many unprepared to manage and overcome the institutional barriers and invisible punishment associated with a criminal record which affected desistance and reentry progress. Overall, these assorted processes produce abrupt and fluid changes and fosters progress and setbacks. Relativity is central to the reentry process; each individual will experience a unique trajectory that includes an assortment of intra-individual experiences that may or may not foster short-term or long-term desistance (Kazemian 2007). 


\section{METHODOLOGICAL APPROACHES TO DESISTANCE RESEARCH}

Qualitative methods rooted in narrative psychology have been instrumental in generating insights on the meanings individuals attribute to their reentry experiences and signal potential avenues for transformation (Maruna 2001). According to King (2013), self-narratives allow one to observe how individuals distance themselves from past events, reflect and generate meaning about events and experiences, and construct new identities (see also Hochstetler, Copes, and Williams, 2010; Stone 2015). In most instances, narratives are offered retrospectively (Veysey et al. 2013). Indeed, available qualitative research often uses cross-sectional designs with prompts for reflection about the past. Desistance or persistence are constructed and labeled a priori through the use of self-report, criminal history, or collateral contact information. With the benefit of hindsight, key choices and turning points made at specific periods of time are clear.

It is not known if such classifications are accurate. First, these retroactive approaches may place too much emphasis on agency due to attribution biases by interviewees, in which desisters attribute their success to internal/stable sources, and persisters highlight external/unstable sources (Zuckerman 1979). Individuals can reflect and recall situations associated with structural influences, but the interaction between agency and structure in an immediate context is lost. Stated differently, such approaches may only capture notions of what one has become rather than what one is currently experiencing in the present moment. Second, future actions may be inconsistent with an expressed narrative, which may invalidate initial trajectory labels (LeBel et al. 2008; Weaver 2013).

An alternative to this approach is to examine self-narratives prospectively, in which individuals are interviewed multiple times over the course of their reentry and speaking to one's understanding, thought processing, and mindset in a relatively more immediate context. The use 
of such an approach has noted advantages over cross-sectional, retrospective means of collecting longitudinal data (Menard and Elliot 1990; Morris and Slocum 2010; Kazemian and Farrington 2005), with important implications for reentry research. Prospective longitudinal interviews allow researchers access to narratives as individuals move towards or away from desistance, establishing the temporal ordering of salient experiences. Importantly, interview data are captured within one's immediate social environment filled with an assortment of structural constraints and reentry challenges that are currently being managed. As such, data generated from these research designs capture agency-structure interactions and are more accurate due to the collection of information while participants are actively transitioning to society. Furthermore, this approach minimizes the recall and attribution biases associated with retrospective longitudinal designs (Menard and Elliot 1990).

This research seeks to add to the growing body of qualitative research on desistance by reframing the focus on the processes experienced by individuals recently released from prison. With the use of a prospective longitudinal panel design, it is possible to explore perceptions of one's capacity to desist and provide some evidence on how and why initial optimism for desistance falters or comes to fruition as individuals transition into the community.

\section{METHOD}

\section{Participants and Design}

Data for the present analysis come from semi-structured longitudinal panel interviews with 39 individuals recently released from prison to a small, industrialized, Midwestern U.S. city. Relative to statewide U.S. Census (2014) indicators, the city was comprised of larger proportions of racial minority residents, higher levels of residential mobility, poverty, and earnings income from public assistance, and lower rates of homeownership and per capita 
earnings income. Unemployment rates in the city ranged between $10 \%$ and $17 \%$ during the study period (U.S. Bureau of Labor Statistics 2014). In short, following their incarceration study participants were returning to a city that was dramatically different than the not-too-distant past, marred by substantial increases in socioeconomic disadvantage and joblessness. Given this research occurred during peak periods of mass incarceration in the study state, the number and frequency of releases to the study city were also at an all-time high.

Eligible participants were identified during pre-parole assessment. Anticipated release to the study city, internal COMPAS risk assessment scores (see Northpointe Institute for Public Management 1996), and criminal history records requiring intensive parole supervision with frequent in-person reporting were the primary criteria for the determination of eligibility. In effect, these factors established a particular eligibility pool of moderate to high risk individuals and excluded low risk individuals. In an effort to minimize disproportionality of representation, conviction offense types were closely monitored as the sample was built. The objective here was to allow variability of offender types to the extent that they mirrored national and study state distributions by conviction offense type.

The first 39 eligible participants who consented for participation formed the final sample. None of the eligible participants refused participation. One-on-one, face-to-face interviews began immediately after consent was obtained in a private room at the parole office. The interview protocol was modeled after previous research (Visher, LaVigne, and Travis 2004). Interview items were broad and open-ended, allowing participants to express thoughts held most salient (Bottoms et al. 2004; Maruna 2001). The same interview items were used across interview waves. Interviewer probes were actively used to gain clarification and allow further elaboration. 
In most instances, these probes were unstructured. All interviews were audio recorded and transcribed. Participants were paid \$20 per interview as compensation for their time.

All of the participants were male. The average age of the participants was 37 years old $(\mathrm{SD}=8.67$; range of $21-56)$. Most $(\mathrm{n}=26,67 \%)$ were African American, with the remainder being White $(n=13)$. Sixty-two percent $(n=24)$ had previously served a prison term. For the current conviction, the most frequent offense term was for a crime against persons $(n=16,41 \%)$, followed by property $(n=14,36 \%)$, drug $(n=5,13 \%)$, and sex offenses $(n=4,10 \%)$. Participants were incarcerated for an average of 5 years $(\mathrm{SD}=3.77$; range of $1-14)$ prior to being released. A series of up to four interviews were scheduled to be conducted across three month intervals during the first post-release year. Subject attrition posed challenges for this intended design, despite direct correspondence with participants and supervising parole agents, the use of off-site public interview locations, approved access to the local jail and rule violation center to interview participants in violation of their supervision, incentivized participation, and research team-participant rapport. Parole transfers to other jurisdictions, termination or suspension of community supervision terms, and absconding from supervision were common impediments that prevented participants from completing subsequent interviews. Acknowledging the inherent difficulty of using a longitudinal panel design with a transient population, the study reported here uses data on the first three waves of interviews.

The first interview was administered upon release or shortly after release, with 6 days being the median duration between release from prison and the first interview. Seventy-seven percent of the sample $(n=30)$ completed interview two, while $31 \%(n=12)$ participated in the third interview. These rates of attrition are similar to past research involving longitudinal panel 
samples of released prisoners in Baltimore (Visher et al. 2004). The median time between interviews one and two was 179 days, and 122 days between interviews two and three.

To assess the potential of biased attrition, a series of nonparametric bivariate tests were employed. Participants who completed interview two were compared to those who could not be interviewed. A similar procedure was used to compare those who did and did not participate in interview three. There were no significant differences between these participant subgroups on background variables consisting of demographic, current offense, criminal history, and risk score measures. This suggests that attrition is either random or affected all participants similarly.

\section{Measurement Strategy}

This research emphasizes the presence and nature of change and how desistance themes manifest over time. This study draws on previous research to build a standardized protocol and code for explicit themes within the participants' narratives. Specifically, the current effort focused on analyzing the participants' responses to prompts asking them to look to the future and discuss what they personally believed were the most important factors to staying out of prison, and why these factors were important. Desistance themes and sub-themes to be coded were derived from the work of Maruna (2001) - who used protocols from McAdams (1992) - and the subsequent partial replications of Maruna's work (Farmer et al. 2012; Healy and O'Donnell 2008; King 2013; Liem and Richardson 2014; Stone 2015). These sub-themes fell under the major thematic areas of agency (self-mastery, status, achieved responsibility, empowerment), generativity (caring, contribution, children, need to be needed, productivity), and identity development (contamination and redemption). As the themes informed by these sources are described extensively elsewhere (Farmer et al. 2012; Healy and O'Donnell 2008; Maruna 2001), we withhold the discussion here and discuss relevant themes in the course of the findings. 
This research deviates from extant replications of Maruna (2001) in two important regards. First, no a priori assumptions about individual trajectories - desisters versus persisters are made. Maruna (2001) was able to make comparisons of individual trajectories by design with two snowball samples of ex-offenders from a larger study. The focus here is to observe desistance organically as it unfolds during the reentry transition. Second, two additional themes age and contingency - emerged during the coding process that are not directly coded in Maruna (2001). Both of these themes begin to expand the focus from subjective desistance factors to include structural constraints that may shape desistance processes (Farrall and Bowling 1999; Paternoster and Bushway 2009).

Age refers to expressions of aging out, getting old, growing up, or maturity due to growing older. Aging is an underlying component of the desistance literature (Laub and Sampson 2003; Paternoster and Bushway 2009). Much of the emphasis is centered on sustained declines in criminal activities with the progression of time as well as age-graded opportunities and avenues for informal social support that affect individual experiences. Contingency relates to expressions of current or future progress in transforming one's identity and remaining crime being dependent, to a variable degree, upon another factor that is a part of one's personality or character or can be found in one's social environment. Gleaned from one of the underlying theoretical propositions of control balance perspectives (Tittle 1995, 1999; Tittle, Ward, and Grasmick 2004), contingencies reflect differences between one's desire to exercise self-control and their capacity to do so. In the context of the current inquiry, the emphasis is on "if, then" desire conditionals offered by participants that affects their ability to actualize desistance. That is, there is expected variation in the use of real or perceived contingent conditions as well as combinations of factors that are manifested over time which shapes one's ability to desist. 
Interviews resulted in a wealth of rich data insights on one's ability to desist during the reentry transition and how this capacity may change over time. In the analysis, a two-step procedure was used to identify patterns and influential themes for elaboration and standardize the relative importance of themes across participants and time. First, all of the themes were coded in as being present (1) or absent (0) within each of the participants' narratives across all of the available interviews. Themes were then coded following a narrative psychology procedure that assigns a weighted score associated with the strength with which views are expressed (see Anderson 2006; Maruna 2001). The weighted score ranges in value from 2 (strongly held) to -2 (strongly rejected or opposing), with the absence of a theme receiving a score of -1 . This procedure corrects for the possibility of overestimating the importance of a given them (i.e., importance being driven by only a few participants). ${ }^{i}$ Contingency themes were not given weighed scores during coding. It was difficult to apply a weighted score to contingency expressions given contingencies themselves were often used to emphasize or deemphasize the importance of other narrative desistance themes. Results are presented by representative patterns existing within the data, a presentational approach used in previous reentry research (see Garland, Wodahl, and Mayfield 2010; Harding et al. 2014; Nelson, Deess, and Allen 1999). An inter-rater reliability sample was drawn consisting of all participants who were interviewed three times $(\mathrm{n}=12)$ and a random selection of eight other participants, comprising 51 percent $(\mathrm{n}=20)$ of all interviewees in the sample, and covering 67 percent of all interviews conducted. Cohen's kappa (Cohen 1960) was used to estimate agreement on the presence of themes between two coders. A bootstrapped kappa of $0.75(\mathrm{SE}=0.02)$ was estimated across 5,000 replicates of the reliability sample, reflecting substantial agreement between the raters. For 
the weighted scores, a quadratic weighted kappa (Cohen 1968) was utilized. A substantial degree of agreement was indicated, with a bootstrapped weighted kappa of $0.75(\mathrm{SE}=0.02)$.

\section{RESULTS}

\section{Critical Desistance Factors Identified at Baseline}

The first step is to examine the prevalence and importance of narrative themes at the first interview to establish a baseline for subsequent comparison (see 'Time 1' in Table 1). At this point the most common themes discussed as being important to desistance concerned caring (74\%; weighted value of 0.64$)$, self-mastery $(69 \% ; 0.31)$, identity development $(67 \% ; 0.38)$, and empowerment $(67 \% ; 0.23)$. To put these observations in perspective, the least important themes for participants were redemption scripts (23\%; weighted value of -0.49), status attainment (8\%; 1.08), and contamination narratives $(5 \% ;-0.87)$. Internal contemplations of the self, concern for extending the self, and initiating or furthering identity work post-release appear to be strongly emphasized following release. To elucidate the critical factors offered by participants and determine why caring and identity work were expressed with such importance to moving on from criminal behavior at baseline, it is important to observe the context and sub-themes of the overarching narrative themes guiding this research.

\section{Generativity Theme of Caring}

Narratives on the ability of one to care for others and to take care to not do something destructive (Maruna, 2001) tended to fall into two forms of expression. First, participants offered insights on the importance for caring for themselves $(n=18,62 \%$ within caring). Marcus, for instance, needs to focus upon, listen to, and worry about himself and recognize his potential for self-destruction. Rather than being a resource for other individuals, the emphasis here is on the care and improvement of the participants themselves. This includes the application of what one 
has experienced and learned throughout their life and especially during their period of recent incarceration. Participants spoke of being present, aware, and open to learn and maintain perspective in the face of anticipated challenges. Agenda and goal setting were discussed as being a key mechanism to take care to develop one's sense of self. Dan is planning to work on [k]eeping a positive attitude and staying focused on bettering myself and you know just not get caught up in the mundane aspects of everyday life, instead, just focus on what I need to do and make sure that I do it.

Another important layer of care was associated with notions of avoiding or minimizing harm to one's self. The main harm to be avoided during the first interview was the potential for contact with the criminal justice system and subsequent return to prison. This threat can be minimized by approaching social encounters with a heightened sense of caution, staying away from and ending relationships with certain people, and generalized notions of maintaining a focus on the future. Beyond system contact, participants also wanted to minimize harm to themselves by repairing losses. Time with family and close members of one's immediate social network is an important commodity in reintegration. Some lost those they cared about most while incarcerated, others still had social supports in need of reunification. Attending to these relationships would enhance protective factors and minimize harm to one's self.

Second, participants discussed the fulfilment of a role and the re-inheritance of a title as important to desistance $(\mathrm{n}=16,55 \%$ within caring). This could involve reestablishing one's previously held role or acting upon a new, modified, or idealized role of what one should be for a given title. Participants spoke of being an assortment of roles. These could be generalized (e.g., citizen, family member, close to extended family), or much more specific (e.g., being there for one's children and grandchildren). In either approach, there is a fundamental acknowledgement 
of a reciprocal and reinforcing relationship between one's role or title and social others who are close to the participant. Dustin has taken a "full reality check" on being a father stating:

I realize that I've hugged the streets more than I've hugged my own children. To see them grow up now, and be like, 'ok, if you're coming home, you're coming home. Ok, you not, you not.' I mean it's painful when you get cussed out by a loved one that's your child, that's 18 or 19 now. I just really want to make things happen for them.

While within the realm of the conceptualization of achievement or responsibility, expressions of roles and titles discussed here do not involve self-determinations of success or achievement outcomes and do not include new responsibilities.

Agency Theme of Self-Mastery

Self-mastery concerns attempts to master, control, enlarge, or perfect one's self, attain insight to the meaning of one's own life, or experience enhanced sense of control over one's destiny (Maruna, 2001). To a large extent, self-mastery themes involved discussions of taking charge of one's life. This could be accomplished by emphasizing one's potential and putting one's self first. Self-made plans and determinations of one's own path were discussed as being central to controlling the future ( $\mathrm{n}=17,63 \%$ within self-mastery). For Cliff this meant pursuing his interest in music and showing his guitar playing skills. This prioritized focus helps to keep participants away from perceived sources of negativity and notions of pleasing others. Equally important is the ability to acknowledge old notions of self, shed these visions, and move forward ( $n=12,44 \%$ within self-mastery). Richard spoke of seeing the change in his own personality and views of the world through volunteering and mentoring opportunities to help others. Additionally, reflection and understanding disconnects between past and present selves provided participants with meaning. 
Much effort was being put into the theme of identity development and change during the first interview. Participants spoke of two interrelated sub-themes relevant to the transition to community life. First were expressions of being "a normal person," disconnected from a previous history of offending. Discussions of normality were focused on internal or external labeling and the simplification of the self to such labels or titles ( $\mathrm{n}=10,38 \%$ within identity). Tim was just a drug addict, Gary was just a child needing immediate gratification, Leslie was just a rebel, and Ken was just a hustler after money and females. Second were elaborations of specific components of one's past personality identified as being problematic that have changed or are in the process of being changed upon release $(n=16,62 \%)$. While overlapping with notions of normality, the key differentiation here is the larger self remains intact, rather than viewing the self as being reduced to a single label (see Hochstetler et al., 2010). Social and peer groups appeared problematic for creating "group think" mentalities and the desire to prove oneself to others. To foster a new or modified identity, the emphasis is refocused on the self"just doing me" - without the influence of social others from one's past.

Old selves were viewed as not possessing or not applying specific cognitive thinking or emotional management skills. Calvin viewed his past self as being passive and "stupid" for not thinking and not caring about the future. Dan strives to set priorities and is attempting to realize his own potential upon release, notions that the old Dan would not have ever considered. Insight of one's lack of initiative struck Robby, who came to the realization prior to release that he needed to take advantage of all offered opportunities and not be afraid to show emotion while doing so. Reflective appraisals of thoughts, feelings, and attitudes were important to participants who spoke of identity transformation. The extent to which these narratives represent "therapy talk" (see Leverentz 2014) is difficult to determine, but the fact that participants express 
narratives in these terms does provide evidence on the importance of reflection and distancing what one was from what one can or will be.

Agency Theme of Empowerment

Empowerment narratives speak of an enhanced sense of self that comes from a variety of external, higher order sources (Maruna, 2001). Participants felt empowered knowing that someone or some metaphorical entity was on their side who could provide tangible or intangible resources when needed ( $\mathrm{n}=16,62 \%$ within empowerment). Ken's girlfriend helps to structure his time and opens the door to new opportunities, Kenny's twin daughters constantly remind him "to stay out of trouble," and drive him "to want to make it," and God will show Dustin the correct path and keep him straight. Participation in activities were also a source of empowerment $(\mathrm{n}=5,19 \%)$. Exposure to various classes and groups came from parole agent referrals. Activities provided psychological and emotional fulfilment plus a connection to similarly situated others. A handful of participants expressed feelings of empowerment that came from serving time in prison $(\mathrm{n}=4,15 \%)$. For instance, Travis is wary of the "tail" on his sentence if he is sent back to prison. This latent threat is an empowering motivator to remain crime-free. In a few instances, participants spoke about the importance of placing themselves first and how this was empowering in and of itself $(n=4,15 \%$ within empowerment). Wilber states, "I want to get myself together first, so right now I'm just keeping to myself, I'm not going to stop doing what I gotta do, I just gotta keep going and just stay positive.” Across all of these cases, sources of empowerment amplified one's sense of self.

[INSERT TABLE 1 HERE - THEMATIC PREVALENCE / WEIGHTS]

\section{Change in Critical Desistance Narrative Themes over Time}


To explore changes over time, variation in themes across interview waves were examined. These trends are displayed in the Time 2 and Time 3 columns of Table 1. Concerning the most prevalent and important themes at the baseline interview, empowerment was the only theme observed to have a linear change with a slight decrease over time. Indeed, it was the most prominent narrative among participants for the second interview, but was not among the highest proportions or strongest weighted importance at the third interview. The remaining prominent baseline themes showed non-linear prevalence patterns over time. Care decreased between interviews one and two, and then increased at interview three to remain at a similar level as the first interview. Self-mastery and identity also decreased and then increased over time, but these two themes were observed at lower levels than the first interview. Nevertheless, caring and selfmastery were among the most prominent and important narratives across all of the subsequent interviews. Narrative themes related to identity were substantially lower at the third interview relative to the first interview and was no longer among the most common narrative themes across subsequent interviews. Rising to prominence with time were narratives speaking to productivity, the need to be needed, and contingencies. Each of these themes are discussed in turn.

\section{Generativity Theme of Productivity}

Productivity concerns expressions of development and growing through outlets to be creative or productive and involves the further growth and development of one's self with emotional investment (Maruna, 2001). Narratives on productivity focused on making commitments to and investments in local services and the referral network of providers used by the parole field office upon release ( $n=7,47 \%$ within productivity at interview one). Akin to Granovetter's (1973) concept of weak ties, local service providers and referral networks have the ability to provide informational or emotional support, expand participants' current social 
network, and facilitate new opportunities with little to no emotional investment needed on behalf of those using the provider or network. Participants presumed that the weak ties made available to them would provide future benefit after introductory discussions were held between the participants and provider representatives.

William viewed employment readiness classes and substance abuse treatment as being critical to putting his mind to work, keeping busy, and being productive. Wilber planned to use an array of available social support groups to remain focused and drug free. Across subsequent interviews, weak ties continue to be important outlets that are used and interacted with to future self-development $(n=4,27 \%$ within productivity at interview two and $n=1,20 \%$ at interview three). In most instances, the weak ties participants used at the time of interview one produced new networks of affiliation with other community social services. Working or going to school contributed to productivity narratives $(n=4,27 \%$ within productivity at interview two and $n=1$, $20 \%$ at interview three). Perhaps most important to productivity narratives are victories regardless of their symbolism, long-term, or short-term effects. Participants spoke of their ability to set goals, fulfill objectives, and establish new benchmarks to achieve $(n=9,60 \%$ within productivity at interview two and $\mathrm{n}=4,80 \%$ at interview three).

Generativity Theme of the Need to be Needed

Participants who expressed need to be needed narratives post-release emphasized the reestablishment of relationships with immediate family members to gain intangible, nonjudgmental support familial networks can offer $(n=8,60 \%$ within needed at interview one). Participants also expressed desires to find one's own community $(n=6,40 \%$ within needed at interview one). For instance, Tim plans to utilize weak social ties from local service providers and agent referrals to find a support network where he can be involved and feel that he is a part 
of society. A focus on becoming welcomed, integrated, and needed by familial networks and one's community is thought to enable the actualization of self-made goals and remove or keep the wrong crowd of peers at a distance. Family and the feelings of welcoming that come from being involved one or multiple community groups continue to fulfill a central purpose for participants with the progression of time $(n=6,46 \%$ and $n=7,54 \%$ respectively within needed at interview two). Jim recognizes the importance of his family during his second interview after experiencing the extent of support his immediate family members could provide. Robby has found a self-help group and has begun volunteering. Brian has made connections in his required substance abuse treatment classes. Similar patterns observed during interview two emerge for the final interview ( $n=5,71 \%$ family and $n=3,43 \%$ community within needed at interview three). At this point William was placed in transitional housing and now values the roles and responsibilities that come with being a roommate.

One issue to consider is the consistency of desistance narratives across interviews. Focusing on the 12 participants interviewed in all three waves, we utilized Yule's Q (Yule 1912) as a non-parametric indicator of thematic consistency across time (see Table 1). A Q of 1 indicates a positive association (i.e., those [not] raising a theme at a given time did the same at a later time), and Q of -1 suggest a negative association (i.e., those [not] raising a theme at a given time did the opposite at a later time), and a Q of 0 suggests no association. The results in Table 1 suggest both consistency and variation in thematic prevalence over time. Participants were consistent in endorsing or not endorsing agency themes (i.e., self-mastery, responsibility, and empowerment) during the study period, and gave similar treatment to aging, identity transformation, and being there for children as important to desistance. On the other hand, several themes were not consistent across time. As considered above, productivity and the need 
to be needed changed across waves, becoming consistently held later during reentry.

Contingency themes were consistent between interviews 1-2, and 1-3, but this theme appeared to change in importance between the $2^{\text {nd }}$ and $3^{\text {rd }}$ interviews. The next section explores this theme in additional detail.

\section{Desistance as Being Contingent on the Reentry Environment}

Despite the strong emphasis on personal agency and self-mastery, narrative themes emphasizing contingencies provide some insight on how the capacity to desist could be mediated by specific factors in one's social environment. Despite the vast majority of participants desiring change and being optimistic regarding their ability to stay away from crime, more than half $(\mathrm{n}=$ $23,62 \%)$ spoke of progress being contingent upon one or more factors during the first interview. Common contingencies discussed in the first interview included gaining employment $(\mathrm{n}=10$, $43 \%$ within contingency), staying away from drugs $(n=6,26 \%)$, being compliant with one's parole officer or conditions $(n=4,17 \%)$, and staying away from the wrong people $(n=3,13 \%)$. Willie notes,

the only way I'm going to get in trouble again is if I go back to drinking because I didn't start doing drugs until I was drinking, wasn't smoking until I was drinking, everything that I've ever done wrong in life drinking was involved.

Participants suggested that if these factors are accomplished, then the likelihood of returning to crime and prison is lessened and their ability to actualize desired changes increases.

At the second interview, gaining employment $(n=10,56 \%$ within contingency) and staying away from drugs $(n=6,33 \%)$ continues to be a common contingency expressed by participants. Employment obtainment has two meanings. Most participants are still awaiting their first payroll hire from an employer; a position that is more stable than working as a handyman or for odd or cash jobs. Travis has actively searched for employment since release and has been 
doing handyman work on automobiles and houses, but has not found a good job that would enable the rest of his life to fall into place. For a few participants, gaining employment means discarding current employment for new opportunities. These narratives tend to focus on one's current employment being a stepping stone to something better. Otis has worked as a production worker for a local clothing manufacturer for the past three months. The job provides an income, but he is having difficulty paying bills and needs to find a new job with higher pay.

Finding and developing a network of social support via weak ties with local agencies becomes an important contingency during interview two ( $n=4,22 \%$ within contingency). These networks tend to start from social service, religious, support, and treatment groups and evolve to include a web of other networks. Brian has been active with his participation in an employment training program and through his participation was linked to a non-profit who works to prevent recidivism through mentorship. Participation in both of these forms of social support is helping to keep him busy and focused.

Staying away from drugs continues to be an important factor among participants across all three interviews $(n=6,33 \%$ within contingency at interview two, $n=3,33 \%$ at interview three). With the progression of time, the likelihood of drug use and/or relapse increases. Participants who spoke of staying away from drug use all had been using off and on for some period of time with much of their use being undetected. At interview two, Willie was working for a friend who owned a bar: "working caused problems, when I had a paycheck coming in it caused problems, [the owner] didn't give a fuck if I was drinking or not as long as I got the job done" which contributed to "two drinking violations, even though [the parole agent] didn't give no breathalyzer." Willie switched to “drinking beer because I don't get as messed up as I do with malt liquor" at interview three. 
Meeting the expectations of parole officers and/or remaining compliant with parole conditions became salient again in the third interview ( $n=4,44 \%$ within contingency).

Generally, these narratives involve participants who have had previous interactions with their parole officer that resulted in some form of sanction perceived to be unfair or unwarranted. Given that such sanctions were enforced near the completion of a parole term contributed to narratives that were skeptical or cautious. For Samuel doing exactly what his agent tells him to do grants the ability to remain in the community and free of violations.

\section{Validation Check: Thematic Prevalence and Importance among Desisters and Persisters}

To this point, this research has examined desistance as a subjective phenomenon, considering how factors found to be relevant to long-term desistance are engaged with by individuals under correctional supervision during the immediate reentry experience, and whether these factors vary with time, regardless of the compliance or recidivism outcomes for the sample. It would be misleading, however, to insinuate that every participant in the current sample desisted from offending. To be clear, there is no known dichotomy between desisters and persisters as desistance is generally considered to be a fuzzy area between these classifications (Maruna, Porter, and Carvalho 2004; Rydberg and Grommon, 2016). The following sub-analysis splits the sample by "desisters" and "persisters" to examine variation in thematic prevalence and weighted importance, with desistance defined as a successful discharge from parole $(n=19$, 48.7\%), and persistence defined as being returned to prison or being censored after parole continuations due to chronic non-compliance $(\mathrm{n}=20 ; 51 \%)$.

The results in Table 2 suggest several points of departure between desisters and persisters. Concerning the presence of themes in the participants narratives, desisters were more likely to describe achieved responsibility (Time 2), being productive (Time 2), redemption (Time 
3), and contingencies (Time 1 and 2). Persisters were more likely than desisters to describe needing to be needed (Time 2) and the desire for identify transformation (Time 3). Concerning the weighted importance scores, there were several contrasts to note. More important to desisters were self-mastery (Time 1), achieved responsibility (Time 2), productivity (Time 3 ) and redemption (Time 3). More important to persisters were the need to be needed (Time 2), achieved responsibility (Time 3), contribution (Time 3), and identity transformation (Time 3). Otherwise, thematic prevalence and importance were relatively similar between the groups. The most pronounced differences between persisters and desisters appeared in the second and third interviews, suggesting that despite similarities at baseline, differences in desistance narratives begin to manifest early into the reentry processes.

[INSERT TABLE 2 HERE - THEMES AMONG DESISTERS AND PERSISTERS]

\section{DISCUSSION AND CONCLUSION}

Previous research has documented that individuals who desist from crime offer different narratives from those who persist in offending, with variable emphasis on agency and structural contingencies. This previous research has focused almost exclusively on long-term desistance factors that will differentiate desisters from persisters with these two groups being constructed by purposive sampling strategies or retrospective research designs. The current study considered the deployment of desistance promoting factors by a cohort of individuals during the immediate reentry process. The goal of the study was to determine the prevalence and importance of these factors at the time of release from prison, and consider how the early reentry process can structure changes in these factors. 
The findings provide evidence that the factors which Maruna (2001) highlighted as important components of long-term desistance narratives were being espoused by participants within the first several months of release. Dimensions of agency, generative activities, and identity work were identifiable in the narratives of participants. Specifically, at the first interview themes of caring, self-mastery, identity change, and empowerment by association with social others were prevalent and consistent in the narratives of participants describing factors that would keep them out of prison. To this extent, the individuals described themselves as enmeshed in a process of "working on me" which involved a variety of activities including taking care to avoid risk factors and acquiring a sense of purpose by associating with prosocial entities. Additionally, participants discussed insight they had gained into problematic aspects of their own conduct and cognitions and their commitment to rid themselves of those elements as well as external components which would place them at risk of returning to prison.

The results of this study contrast with research suggesting that identity-driven desistance begins after time in the community (Healy and O'Donnell 2008). Instead, this research finds that individuals are actively engaging in desistance promoting factors as soon as they are released from prison. Furthermore, the themes discussed most prominently at release largely concerned identity work. The benefit of utilizing prospective longitudinal interviews was the ability to follow up with participants throughout the reentry process to capture changes in these factors over time. Across subsequent interviews it was observed that some identity work continued, particularly as individuals maintained the importance of caring and self-mastery. Yet, the desistance factors cited as rising in importance in the later interviews tended to reflect one's navigation of the material dimensions of the reentry process. That is, participants gave increasing emphasis to making progress towards goals, developing and utilizing social networks, while 
noting that staying out of prison was becoming increasingly more contingent on securing employment and staying away from criminal associates. Differences between individuals moving towards desistance and presumably managing these difficult reentry challenges versus those who are moving away from desistance are beginning to become distinguishable six to ten months after release from prison.

In combination, these patterns suggest that individuals do not work on particular desistance factors in mutually exclusive or sequential blocks, such as first meeting basic needs, then moving to identity work once those are met. Rather, identity processes are consistently worked on during reentry, but the subjective importance of these factors is mediated by the material constraints of reentry. One important construct to measure in this process would be the psychosocial strains experienced by individuals during this process (Garland and Wodahl 2014). The findings of the current research imply that failure to actualize desired identity change in the face of environmental contingencies may contribute to stress and cognitive dissonance, particularly at later points during the reentry process. How such strains impact both the process and outcomes of reentry transition is an important consideration for future research.

These findings temper desistance theories which place heavy emphasis on individual agency in the face of structural constraints (LeBel et al. 2008). The participants in this sample conceptualized and honed "future selves" (Giordano et al. 2002; Paternoster and Bushway 2009), and articulated their desires to own those conceptions in their interview at release. However, the practicalities of the reentry process were presented by the interviewees as obstacles to actualizing reformed identities. To this extent, Archer (2000) provided an accurate description of agency, identity work, and desistance as they play out during the reentry process. In the course of reentry, individuals are required to navigate new, pro-social roles to maintain desistance, and as they 
commit themselves to these roles they begin to define and actualize their identities as individuals who are moving away from criminality. Yet, Archer's (2000) agent is an individual who actively confronts and evaluates their environment, simultaneously engaging with physical, practical, and social orders of reality. As indicated by Bottoms (2006), the practical order of reality has powerful implications for the realization of identity-driven desistance. As the current research suggests, if individuals are unable to achieve in the material requirements of their new nondeviant roles then up-front identity work can be effectively neutralized. In other words, reentry challenges create barriers to realizing even the sincerest intentions to desist from offending. Scholars examining how reentry is experienced directly from the offender perspective and its interrelationship with desistance should integrate and further refine Archer's (2000) theoretical contributions.

Participants in the current study engaged with desistance promoting factors shortly after release. A practical issue becomes whether anything can be done to assist individuals transitioning to the community in the actualization of identity transformation. The results of this study identify important implications for criminal justice and social service intervention in the reentry process. Components of Good Lives Model (GLM) provide a fertile ground for building desistance capacity. GLM is a strength-based approach which casts criminogenic needs as internal or external barriers towards individuals achieving core values and life priorities (Ward, Yates, and Willis 2012). GLM's architects posit that all humans are predisposed to seek "a good life", conceptualized as the pursuit of primary goods (e.g., knowledge, autonomy, and community, among others [see Laws and Ward 2011]). Criminal behavior is contended to take the form of utilizing anti-social instrumental means to secure these primary goods. Deficiencies in means represent possible contingencies in the capacity to desist from offending. 
Proponents of the GLM claim that a practical strength of the model is that it is capable of identifying primary goods important to individual offenders, and the resources available to them for actualizing these goals (Willis and Ward 2011). In the context of reentry on parole, information on desired goods and deficiencies in means can be gathered through efforts to enhance the therapeutic alliance between parolees and their parole agents. Recent efforts to improve the effectiveness of community supervision through motivational interviewing (Walters et al. 2007) or training models such as Strategic Training Initiative in Community Supervision ([STICS] Bonta, et al. 2013) and Effective Practices in Community Supervision ([EPICS] Smith, Schweitzer, Labrecque, and Latessa 2012) have shown promise. In the context of the current inquiry, approaches to improve the quality of the parolee-parole agent relationship should be expanded. An important goal for parole agents would be to identify the primary and secondary goods which would be most conducive to an individual's identity change. Collaboratively, the parolee and parole agent can identify structural and environmental contingencies which would impede the actualization of this change, and develop pro-social strategies for overcoming these contingencies, along with continuous follow-up during the reentry process. This approach may be more sensible than current policy and practice that takes a front-loaded "shotgun" approach to reentry that hopes that out of a pool of local services and opportunities something will "hit" and build one's capacity to desist (Jonson \& Cullen, 2015).

For instance, in the current study one of Glen's follow-up interviews took place from jail, following his re-arrest on a drug charge. He noted that by getting involved with a young woman, his reentry was moving "too fast", and without enough financial resources to support the two of them and no luck in the employment market, he turned to drug dealing to take on his role as a provider. In this particular case, Glen's pursuit of legitimate primary goods (i.e., companionship, 
autonomy) were met by the hard realities of the reentry process. With no prosocial means to navigate the physical and practical orders of reality (Archer, 2000), he turned to illegal behavior. Glen's case suggests possible intervention points by GLM-informed supervision. Rather than treating desired primary goods as risks to be avoided (e.g., avoid relationships), desired goods can be made explicit during the pre-parole process, and an incremental plan for building the necessary secondary goods could be formulated and updated as reentry unfolded. This approach may provide heightened motivation for individuals to engage in their supervision and treatment, relative to a regimen solely designed to reduce the likelihood of recidivism (Ward et al. 2012).

A few limitations need to be addressed. First, the findings from this study must be interpreted with issues of generalizability in mind. The sample size was manageably small, was generated from one small Midwestern city, and the rate of attrition was higher than anticipated despite our best efforts to incentivize and maintain correspondence with participants. While it is possible to begin to distinguish those heading towards desistance and those persisting in their criminal behavior with longitudinal designs (Bushway and Apel 2012; Rocque et al., 2016), future research employing panel designs should aim to generate a larger sample that is followed over a longer period of time. Innovative designs employing technology-assisted data collection tools may mitigate some attrition issues and further this line of research while panel participants are in the community (see Sugie 2014). It will also be important to determine if pre-release experiences produce reliable desistance signals that continue to be transmitted upon transition to the community (see Bushway and Apel 2012) as there is little consensus about the timing of when reentry processes begin and end (Garland and Wodahl 2014).

Second, as with any study attempting to directly or indirectly examine desistance, early post-release narratives expressed by the participants do not guarantee that future desistance will 
occur. It is difficult to identify when someone has begun to desist and when they have achieved desistance (Kazemian 2007; King 2013). When interpreting the findings of the current study, it is important to recall that the focus is not on the outcome of desistance. Rather, this research provides insights to how individuals process their own capability to desist given their immediate environment and reentry experiences.

Third, and relatedly, attempts to empirically examine personal agency is limited since complete true self or true self-contextual awareness is difficult to achieve (Bottoms et al. 2004). As noted by Neisser (1994), narratives about the self are "a basis but not the basis of identity" (p. 1). While narratives provide an explanation of one's evolving story and views of the world (Presser 2008; Stone 2015), there is potential for deviations in the description of events and experiences. Narrative psychologists have noted that such errors tend to result from recalls of early life events, although there has been relatively little research seeking to understand present moment experiences (see Prebble, Rose Addis, and Tippett 2012). Research team members attempted to minimize participant impression management by offering periodic reminders of response confidentiality throughout the interview as well as using probing techniques that were individualized to each participant (i.e., follow-up from past completed interviews).

This study contributes to reentry and desistance literatures by providing a deeper, more penetrating understanding of the reentry experience and how individuals frame their identities and cope with obstacles. One of the key conclusions to take away from this research is that individuals experiencing the transition from prison to the community exert narratives that signal a desire and capability to desist upon release. While the desire to desist remains prominent over time, the capability to desist appears becomes increasingly tied to managing the pains of reentry at or after six months of being in the community. Future research should continue to explore the 
complex interconnections between the reentry process and desistance and examine these relationships with other theoretical lenses that directly incorporate structural perspectives (see Paternoster and Bushway 2009) in an effort to further refine knowledge on one's capacity to desist. The current research suggests that the subjective salience of particular desistance promoting factors varies with time in the community, perhaps implying some degree of malleability. What is the role of supervision in this malleability? How can community corrections practice create the best opportunities for its clients to actualize desired identity change? What are the key correlates that influence how one understands their progress moving toward or away from desistance that occur before and after release? Research can also explore how particular successes and setbacks during the reentry process (i.e., employment/housing instability, health challenges, and participation in social services) are related to psychosocial strain, empowerment and disempowerment, and identity transformation. The generation of additional knowledge on individual exertion of agency in the face of constraints, motivation, and decision-making during reentry will greatly benefit future research on desistance capacity. 


\section{REFERENCES}

Anderson, W. P. 2006. "A Procedure for Coding Self-Regard from Narrative Self-Descriptions." Psychological Reports, 99(3): 879-893.

Archer, M. S. 2000. Being Human: The Problem of Agency. Cambridge: Cambridge University Press.

Bahr, S.J., L. Harris, J.K. Fisher, and A.H. Armstrong. 2010. "Successful Reentry: What Differentiates Successful and Unsuccessful Parolees?" International Journal of Offender Therapy and Comparative Criminology 54(5): 667-692.

Bonta, J., G. Bourgon, T. Rugge, C. Gress, and L. Gutierrez. 2013. “Taking the Leap: From Pilot Project to Wide-Scale Implementation of the Strategic Training Initiative in Community Supervision (STICS)." Justice Research and Policy 15(1): 17-35.

Bottoms, A. 2006. "Desistance, Social Bonds, and Human Agency: A Theoretical Exploration." In The Explanation of Crime: Context, Mechanisms, and Development, edited by P. O. H. Wikström and R. J. Sampson, 243-290. Cambridge: Cambridge University Press.

Bottoms, A., J. Shapland, A. Costello, D. Holmes, and G. Muir. 2004. "Towards Desistance: Theoretical Underpinnings for an Empirical Study." Howard Journal 43(4): 368-389.

Bushway, S.D. and R. Apel. 2012. "A Signaling Perspective on Employment-Based Reentry Programming.” Criminology \& Public Policy 11(1): 21-50.

Carson, E.A. 2014. Prisoners in 2013, Washington, DC: US Department of Justice, Office of Justice Programs, Bureau of Justice Statistics.

Cohen, J. 1960. “A Coefficient of Agreement for Nominal Scales." Educational and Psychological Measurement 20(1): 37-46.

Cohen, J. 1968. "Weighted Kappa: Nominal Scale Agreement Provision for Scaled Disagreement or Partial Credit." Psychological Bulletin 70(4): 213-220.

Davis, C., S. J. Bahr, and C. Ward. 2013. "The process of Offender Reintegration: Perceptions of what Helps Prisoners Reenter Society." Criminology and Criminal Justice 13(4): 446469 .

Durose, M. R., A.D. Cooper, and H.N. Snyder. 2014. Recidivism of Prisoners Released in 30 States in 2005: Patterns from 2005 and 2010, Washington, DC: US Department of Justice, Office of Justice Programs, Bureau of Justice Statistics.

Farmer, M., A.R. Beech, and T. Ward. 2012. "Assessing Desistance in Child Molesters: A Qualitative Analysis.” Journal of Interpersonal Violence 27(5): 930-950. 
Farrall, S. and B. Bowling. 1999. "Structuration, Human Development and Desistance from Crime. British Journal of Criminology 39(2): 253-268.

Farrington, D. P. and D.J. West. 1995. "Effects of Marriage, Separation, and Children on Offending by Adult Males." In Current Perspectives on Aging and the Life Cycle, edited by Z.S. Blau and J. Hagan, 249-281. Greenwich: JAI.

Garland, B., and E.J. Wodahl. 2014. "Coming to a Crossroads: A Critical Look at the Sustainability of the Prisoner Reentry Movement." In Offender Reentry: Rethinking Criminology and Criminal Justice, edited by M.S. Crow and J.O. Smykla, 399-422. Burlington: Jones and Bartlett.

Garland, B., E.J. Wodahl, and J. Mayfield. 2011. "Prisoner Reentry in a Small Metropolitan Community: Obstacles and Policy Recommendations." Criminal Justice Policy Review 22(2): 90-110.

Giordano, P. C., S.A. Cernkovich, and J.A. Rudolf. 2002. "Gender, Crime, and Desistance: Toward a Theory of Cognitive Transformation.” American Journal of Sociology 107(4): 880-1067.

Granovetter, M. S. 1973. “The Strength of Weak Ties.” American Journal of Sociology 78(6): 1360-1380.

Harris, A. 2011. "Constructing Clean Dreams: Accounts, Future Selves, and Social and Structural Support as Desistance Work.” Symbolic Interaction 34(1): 63-85.

Healy, D. and I. O’Donnell. 2008. "Calling Time on Crime: Motivation, Generativity and Agency in Irish Probationers.” Probation Journal 55(1): 25-38.

Hochstetler, A., H. Copes, and J.P. Williams. 2010. “That's not Who I am:' How Offenders Commit Violent Acts and Reject Authentically Violent Selves.” Justice Quarterly 27(4): 492-516.

Jonson, C. L. \& F.T. Cullen. 2015. Prisoner Reentry Programs. Crime and Justice, 44(1): $517-$ 575.

Kazemian, L. and D.P. Farrington. 2005. "Comparing the Validity of Prospective, Retrospective, and Official Onset for Different Offending Trajectories." Journal of Quantitative Criminology 21(2): 127-147.

King, S. 2013. "Early Desistance Narratives: A Qualitative Analysis of Probationers' Transitions towards Desistance.” Punishment \& Society 15(2): 147-165.

Kirk, D. S. 2012. "Residential Change as a Turning Point in the Life Course of Crime: Desistance or Temporary Cessation?" Criminology 50(2): 329-358. 
Neisser, U. 1994. "Self-Narratives: True and False.” In The Remembering Self: Construction and Accuracy in the Self-Narrative, edited by U. Neisser and R. Fuvush, 1-18. New York: Cambridge University Press.

Laub, J. H. and R.J. Sampson. 2003. Shared Beginnings, Divergent Lives: Delinquent Boys to Age 70. Cambridge: Harvard University Press.

Laws, D. R., and T. Ward. 2011. Desistance from Sexual Offending: Alternatives to Throwing away the Keys. New York: Guilford Press.

LeBel, T. P., R. Burnett, S. Maruna, and S. Bushway, 2008. “The 'Chicken and Egg' of Subjective and Social Factors in Desistance from Crime." European Journal of Criminology 5(2): 130-158.

Leverentz, A.M. 2014. The Ex-Prisoner's Dilemma: How Women Negotiate Competing Narratives of Reentry and Desistance. New Brunswick: Rutgers University Press.

Liem, M. and N.J. Richardson. 2014. "The Role of Transformation Narratives in Desistance among Released Lifers." Criminal Justice and Behavior. Advance online publication. doi: $10.1177 / 0093854813515445$.

Maruna, S. 2001. Making Good: How Ex-Convicts Reform and Rebuild their Lives. Washington, DC: American Psychological Association.

Maruna, S. and H. Toch. 2005. "The Impact of Imprisonment on the Desistance Process." In Prisoner Reentry and Crime in America, edited by J. Travis and C. Visher, 139-179. Cambridge: Cambridge University Press.

Maruna, S., L. Porter, and I. Carvalho. 2004. "The Liverpool Desistance Study and Probation Practice: Opening the Dialogue.” Probation Journal 51(3): 221-232.

Mears, D. P., J.C. Cochran, and S.E. Siennick. 2013. "Life-Course Perspectives and Prisoner Reentry." In Handbook of Life-Course Criminology: Emerging Trends and Direction for Future Research, edited by C.L. Gibson and M.D. Krohn, 317-334. New York: Springer.

Menard, S. and D.S. Elliot. 1990. "Longitudinal and Cross-Sectional Data Collection and Analysis in the Study of Crime and Delinquency." Justice Quarterly 7(1): 11-55.

Morris, N. A., and L. Slocum. 2010. "The Validity of Self-Reported Prevalence, Frequency, and Timing of Arrest: An Evaluation of Data Collected using a Life History Calendar." Journal of Research in Crime and Delinquency 47(2): 210-240.

Nelson, M., P. Deess, and C. Allen. 1999. The First Month Out: Post-Incarceration Experiences in New York City. New York: Vera Institute of Justice. 
Northpointe Institute for Public Management. (1996), COMPAS. Traverse City: Author.

Paternoster, R. and S.D. Bushway. 2009. "Desistance and the 'Feared Self': Toward an Identity Theory of Criminal Desistance." Journal of Criminal Law and Criminology 99(4): 11031156.

Petersilia, J. 2003. When Prisoners Come Home: Parole and Prisoner Reentry. New York: Oxford University Press.

Prebble, S. C., D. Rose Addis, and L.J. Tippett. 2012. “Autobiographical Memory and Sense of Self.” Psychological Bulletin, 139(4): 815--40.

Presser, L. 2008. Been a Heavy Life: Stories of Violent Men. Urbana: University of Illinois Press.

Rocque, M., C. Posick, and R. Paternoster. 2016. "Identities Through Time: An Exploration of Identity Change as a Cause of Desistance." Justice Quarterly. Advance online publication. doi: 10.1080/07418825.2014.894111.

Rydberg, J. and E. Grommon. 2016. "A Multimethod Examination of the Dynamics of Recidivism During Reentry." Corrections: Policy, Practice, and Research 1(1): 40-60.

Shapland, J. and A. Bottoms. 2011. "Reflections on Social Values, Offending and Desistance among Young Adult Recidivists." Punishment and Society 13(3): 256-282.

Smith, P., M. Schweitzer, R.M. Labrecque, and E.J. Latessa. 2012. "Improving Probation Officers' Supervision Skills: An Evaluation of the EPICS Model.” Journal of Crime and Justice 35(2): 189--99.

Soyer, M. 2014. "The Imagination of Desistance: A Juxtaposition of the Construction of Incarceration as a Turning Point and the Reality of Recidivism. The British Journal of Criminology 54(1): 91-108.

Stone, R. 2015. "Desistance and Identity Repair: Redemption Narratives as Resistance to Stigma." The British Journal of Criminology. Advance online publication. doi: 10.1093/bjc/azv081

Sugie, N. F. 2014. Finding Work: A Smartphone Study of Job Searching, Social Contacts, and Wellbeing after Prison. Washington, DC: U.S. Department of Justice, Office of Justice Programs, National Institute of Justice.

Tittle, C. R., D.A. Ward, and H.G. Grasmick. 2004. 'Capacity for Self-Control and Individuals' Interest in Exercising Self-Control.” Journal of Quantitative Criminology 20(2): 143-172.

Tittle, C. R. 1999. "Continuing the Discussion of Control Balance." Theoretical Criminology 3(3): 344--52. 
Tittle, C. R. 1995. Control Balance: Toward a General Theory of Deviance. Boulder: Westview.

Uggen, C. 2000. "Work as a Turning Point in the Life Course of Criminals: A Duration Model of Age, Employment, and Recidivism.” American Sociological Review 65(4): 529-546.

U.S. Bureau of Labor. 2014. "Current employment and labor force statistics." Retrieved from http://www.bls.gov/data/

U.S. Census Bureau. 2014. "American factfinder fact sheet.” Retrieved from http://factfinder2.census.gov/faces/nav/jsf/pages/index.xhtml

Veysey, B. M., D.J. Martinez, and J. Christian. 2013. "'Getting Out': A Summary of Qualitative Research on Desistance across the Life Course." In Handbook of Life-Course Criminology: Emerging Trends and Direction for Future Research, edited by C.L. Gibson and M.D. Krohn, 233-260. New York: Springer.

Visher, C., N. LaVigne, and J. Travis. 2004. Maryland Pilot Study: Findings from Baltimore. Washington, DC: Urban Institute.

Walters, S. T., M.D. Clark, R. Gingerich, and M. Meltzer. 2007. Motivating Offenders to Change: A Guide for Probation and Parole. Washington, DC: National Institute of Corrections.

Ward, T., P.M. Yates, and G.M. Willis. 2012. "The Good Lives Model and the Risk Need Responsivity Model: A Critical Response to Andrews, Bonta, and Wormith (2011).” Criminal Justice and Behavior 39(1): 91-110.

Weaver, B. 2012. "The Relational Context of Desistance: Some Implications and Opportunities for Social Policy." Social Policy and Administration 46(4): 395-412.

Willis, G. M., and T. Ward. 2011. "Striving for a Good Life: The Good Lives Model Applied to Released Child Molesters." Journal of Sexual Aggression: An International, Interdisciplinary Forum for Research, Theory, and Practice 17(3): 290-303.

Yule, G. U. 1912. "On the Methods of Measuring Association between Two Attributes." Journal of the Royal Statistical Society 75(6): 579-652.

Zuckerman, M. 1979. "Attribution of Success and Failure Revisited, or: The Motivation Bias is Alive and Well in Attribution Theory." Journal of Personality 47(2): 245--87. 
Table 1. Theme Prevalence and Weighted Importance $(\mathbf{N}=39)$

\begin{tabular}{|c|c|c|c|c|c|c|c|c|c|}
\hline \multirow[t]{2}{*}{ Thematic Area } & \multicolumn{2}{|c|}{$\begin{array}{c}\text { Time } 1 \\
(\mathrm{n}=39)\end{array}$} & \multicolumn{3}{|c|}{$\begin{array}{c}\text { Time 2 } \\
(\mathrm{n}=30)\end{array}$} & \multicolumn{4}{|c|}{$\begin{array}{c}\text { Time 3 } \\
(\mathrm{n}=12)\end{array}$} \\
\hline & $\%$ & $\mathrm{M}(\mathrm{SD})$ & $\%$ & $\mathrm{M}(\mathrm{SD})$ & Q 1:2 & $\%$ & $\mathrm{M}(\mathrm{SD})$ & Q 1:3 & Q 2:3 \\
\hline \multicolumn{10}{|l|}{ AGENCY } \\
\hline Self-I & 69 & $\begin{array}{c}.31 \\
(1.44)\end{array}$ & 63 & $\begin{array}{c}.20 \\
(1.65)\end{array}$ & 0.60 & 67 & $\begin{array}{c}.33 \\
(1.61)\end{array}$ & 0.75 & 0.80 \\
\hline Status Attainment & 8 & $\begin{array}{c}-1.08 \\
(.84)\end{array}$ & 13 & $\begin{array}{c}-.83 \\
(1.02)\end{array}$ & 1.00 & 25 & $\begin{array}{c}-.58 \\
(1.00)\end{array}$ & -1.00 & 0.27 \\
\hline Achieved Responsibility & 38 & $\begin{array}{c}-.36 \\
(1.39)\end{array}$ & 53 & $\begin{array}{c}.00 \\
(1.55)\end{array}$ & 0.68 & 50 & $\begin{array}{c}.17 \\
(1.64)\end{array}$ & 0.33 & 0.82 \\
\hline Empo & 67 & $\begin{array}{c}.23 \\
(1.42)\end{array}$ & 67 & $\begin{array}{c}.43 \\
(1.57) \\
\end{array}$ & 1.00 & 58 & $\begin{array}{c}.25 \\
(1.60)\end{array}$ & 0.60 & 0.58 \\
\hline \multicolumn{10}{|l|}{ GENERATIVITY } \\
\hline Carin & 74 & $\begin{array}{c}.64 \\
(1.18)\end{array}$ & 63 & $\begin{array}{c}.45 \\
(1.12)\end{array}$ & -1.00 & 75 & $\begin{array}{c}.75 \\
(1.14)\end{array}$ & 0.00 & -1.00 \\
\hline Contribution & 28 & $\begin{array}{c}-.38 \\
(1.09)\end{array}$ & 20 & $\begin{array}{l}-.57 \\
.90)\end{array}$ & -1.00 & 33 & $\begin{array}{c}-.57 \\
(1.13)\end{array}$ & 1.00 & -1.00 \\
\hline Child & 26 & $\begin{array}{c}-.41 \\
(1.12)\end{array}$ & 27 & $\begin{array}{c}-.40 \\
(1.04)\end{array}$ & 0.80 & 42 & $\begin{array}{c}.08 \\
(1.38)\end{array}$ & 1.00 & 0.20 \\
\hline Need to be Needed & 36 & $\begin{array}{c}-.41 \\
(1.43)\end{array}$ & 43 & $\begin{array}{l}-.17 \\
(1.31)\end{array}$ & 1.00 & 58 & $\begin{array}{c}.50 \\
(1.38)\end{array}$ & -0.33 & -0.60 \\
\hline Productive & 38 & $\begin{array}{c}-.21 \\
(1.17)\end{array}$ & 55 & $\begin{array}{c}.34 \\
(1.52)\end{array}$ & -0.33 & 67 & $\begin{array}{c}.25 \\
(1.54)\end{array}$ & 0.25 & 0.67 \\
\hline \multicolumn{10}{|l|}{ IDENTITY } \\
\hline Cont & 5 & $\begin{array}{l}-.87 \\
(.57)\end{array}$ & 7 & $\begin{array}{l}-.80 \\
(.76)\end{array}$ & -1.00 & 8 & $\begin{array}{l}-.75 \\
(.87)\end{array}$ & -1.00 & -1.00 \\
\hline Redemption Script & 23 & $\begin{array}{l}-.49 \\
(.97)\end{array}$ & 30 & $\begin{array}{c}-.30 \\
(1.12)\end{array}$ & -1.00 & 33 & $\begin{array}{c}-.17 \\
(1.27)\end{array}$ & 0.00 & 0.00 \\
\hline Identity Transformation & 67 & $\begin{array}{c}.38 \\
(1.16) \\
\end{array}$ & 47 & $\begin{array}{c}.03 \\
(1.40) \\
\end{array}$ & 0.33 & 50 & $\begin{array}{c}.17 \\
(1.47)\end{array}$ & 0.33 & 0.92 \\
\hline \multicolumn{10}{|l|}{ CONTEXT } \\
\hline Age & 28 & $\begin{array}{c}-.36 \\
(1.06)\end{array}$ & 20 & $\begin{array}{c}-.50 \\
(1.04)\end{array}$ & 0.60 & 25 & $\begin{array}{c}-.42 \\
(1.08)\end{array}$ & 0.27 & 0.60 \\
\hline Contingency & 59 & -- & 60 & -- & 0.80 & 75 & -- & 0.56 & -1.00 \\
\hline
\end{tabular}

Note: Weights reflect strength of perceptions. Scale -2 to 2 . Not present scored -1 . Midpoint 0 not used in coding. $\mathrm{Q}=$ Yules $\mathrm{Q}$ measuring consistency between the presence of themes across the 12 participants completing all three interviews.

Q 1:2 = Consistency between thematic presence in Interview 1 and 2.

Q 1:3 = Consistency between thematic presence in Interview 1 and 3 .

Q 2:3 = Consistency between thematic presence in Interview 2 and 3 . 
Table 2. Thematic Prevalence and Mean Weighted Importance Score over Time by Status $(\mathbf{N}=39)$

\begin{tabular}{|c|c|c|c|c|c|c|}
\hline & \multicolumn{2}{|c|}{ Time 1} & \multicolumn{2}{|c|}{ Time 2} & \multicolumn{2}{|c|}{ Time 3} \\
\hline & $\begin{array}{c}\text { Desisters } \\
\mathrm{n}=19\end{array}$ & $\begin{array}{c}\text { Persisters } \\
n=20\end{array}$ & $\begin{array}{c}\text { Desisters } \\
\mathrm{n}=15\end{array}$ & $\begin{array}{c}\text { Persisters } \\
n=15\end{array}$ & $\begin{array}{c}\text { Desisters } \\
\mathrm{n}=7\end{array}$ & $\begin{array}{c}\text { Persisters } \\
n=5\end{array}$ \\
\hline & $\%$ (Score) & $\%$ (Score) & $\%$ (Score) & $\%$ (Score) & $\%$ (Score) & $\%$ (Score) \\
\hline $\begin{array}{l}\text { AGENCY } \\
\text { Self-Mastery }\end{array}$ & $84(0.68)$ & $55(-0.05)$ & $73(0.40)$ & $53(0.00)$ & $71(0.29)$ & $60(0.40)$ \\
\hline Status & $11(-1.05)$ & $5(-1.10)$ & $20(-0.67)$ & $7(-1.00)$ & $29(-0.57)$ & $20(-0.60)$ \\
\hline Ach Responsibility & $37(-0.37)$ & $40(-0.35)$ & $67(0.47)$ & $40(-0.40)$ & $74(-0.14)$ & $60(0.60)$ \\
\hline Empowerment & $74(0.37)$ & $60(0.10)$ & $73(0.67)$ & $60(0.20)$ & $57(0.29)$ & $60(0.20)$ \\
\hline $\begin{array}{l}\text { GENERATIVITY } \\
\text { Caring }\end{array}$ & $74(0.68)$ & $75(0.60)$ & $73(0.60)$ & $53(0.20)$ & $71(0.57)$ & $80(1.00)$ \\
\hline Contribution & $26(-0.42)$ & $30(-0.35)$ & $13(-0.73)$ & $27(-0.40)$ & $29(-0.29)$ & $40(0.00)$ \\
\hline Child Care/Nuture & $21(-0.58)$ & $30(-0.25)$ & $33(-0.27)$ & $20(-0.53)$ & $43(0.14)$ & $40(0.00)$ \\
\hline Need to be Needed & $42(-0.37)$ & $30(-0.45)$ & $33(-0.33)$ & $53(0.00)$ & $57(0.43)$ & $60(0.60)$ \\
\hline Productive & $37(-0.26)$ & $40(-0.15)$ & $60(0.60)$ & $50(0.07)$ & $71(0.29)$ & $60(-0.90)$ \\
\hline $\begin{array}{l}\text { IDENTITY } \\
\text { Contam. Script }\end{array}$ & $5(-0.84)$ & $5(-0.90)$ & $0(-1.00)$ & $13(-0.60)$ & $14(-0.57)$ & $0(-1.00)$ \\
\hline Redemption Script & $26(-0.42)$ & $20(-0.55)$ & $27(-0.33)$ & $33(-0.27)$ & $57(0.43)$ & $0(-1.00)$ \\
\hline Identity Trans. & $68(0.47)$ & $65(0.30)$ & $47(0.07)$ & $47(0.00)$ & $43(-0.14)$ & $60(0.60)$ \\
\hline $\begin{array}{l}\text { CONTEXT } \\
\text { Age }\end{array}$ & $32(-0.26)$ & $25(-0.26)$ & $13(-0.67)$ & $27(-0.33)$ & $14(-0.57)$ & $40(-0.20)$ \\
\hline Contingency & $73(--)$ & $45(--)$ & $73(--)$ & $47(--)$ & $85(--)$ & $75(--)$ \\
\hline
\end{tabular}




\section{SUBSTANTIVE NOTES}

iThe assignment of weighted scores is associated with the strength with which narrative themes are expressed. This technique enhances the inter-rater reliability and content validity of measures used in research that are constructed from interview data sources (Anderson 2006). It must be acknowledged that this study, like all research employing qualitative techniques, relies upon data that are co-produced by participants, interviewers, and researchers (Presser 2008). For transparency, the following is an illustration of the weighting procedure used to code two participants who expressed narratives consistent with the generativity theme of caring. During his Time 1 interview, Marcus addresses what will keep him from going back to prison, stating “...myself, basically. I've been known to selfdestruct when things don't go my way. I got self-destruct and put myself in a position like, dude, what was you thinking? My main thing is to focus on me. If I worry about me and get myself together, that's when I can help everybody else. That's going to be my main think to keep me out of prison. Basically, to focus on myself, to listen to myself." Responding to the same interview item during his Time 2 interview, Glen states "...I can honestly say that I never really want to do this situation again. Because, I got people out there that do love me, people who want to see me do right. When I keep putting myself in this situation, people have no choice but to turn their back on you because they feel like, I'm letting myself down, but I'm letting them down as well." Marcus was assigned a weighed score of 2, while a weighed score of 1 was assigned to Glen's statements. Both of the independent coders scored Marcus and Glen with the same weighted score. Additional examples, including a detailed codebook used for the analyses, can be provided upon request. 